\title{
Landslide hazard assessment around MCT zone in Marsyangdi River basin, west Nepal
}

\author{
Subash Acharya and Dinesh Pathak* \\ Central Department of Geology, Tribhuvan University, Kirtipur, Kathmandu, Nepal \\ *(Corresponding email: dpathaktu@gmail.com)
}

\begin{abstract}
In the hilly and mountainous terrain of Nepal, landslide is the most common natural hazard especially during prolong rainfall. Every year landslide cost lives and causes injuries. In order to address this problem, the best that can be done is to prepare the landslide hazard map of the area, apply mitigation measures and evacuate the high hazardous area, if necessary. Landslide hazard assessment is the primary tool so as to understand the nature and characteristics of the slope that are prone to failure. Logistic Regression Model is used for the preparation of landslide hazard map of the Besi Shahar-Tal area in Marsyangdi River basin in west Nepal. The causative factors such as elevation, slope, slope aspect, land use, geology, rainfall, lineament density, stream density are used. All the thematic layers of these parameters are prepared in GIS and logistic regression analysis is done by using Statistical Package for Social Science (SPSS). Five different hazard zones are separated namely very low hazard zone, low hazard zone, medium hazard zone, high hazard zone and very high hazard zone. The high hazard zone is lying along the Marsyangdi River and its tributaries.
\end{abstract}

Keywords: Marsyangdi River basin, landslide hazard, logistic regression, Lesser Himalaya, Nepal

Received: 1 November 2016

Revision accepted: 21 May 2017

\section{INTRODUCTION}

Nepal is mountainous country and the Nepalese mountains are geologically young and tectonically active forming steep slope and unstable landscape. Intense and prolonged rainfall causes landslide, erosion, and slope failure especially during the monsoon season. Landslides are amongst the most damaging natural hazards in the mountainous terrain such as the Himalayas. Landslide in most part of the country causes high level of economic loss and substantial numbers of fatalities every year. The major component that aid for the increase in number of landslide is the haphazard rural road construction activities and the change in land use. The local geology and slope of the area also has significant effect on landslides. In order to minimize the loss due to landslide, landslide prone areas should be identified. Regional and local scale landslide hazard analysis and risk management is essential. Landslide hazard map can be a useful in estimating, managing and mitigating landslide hazards.

Landslide presents a threat to life and livelihood throughout the world, ranging from minor social disruption to huge economic catastrophe. Most work on landslide hazard assessment has been site-based and driven by development projects and engineering concerns (Crozier and Glade 2005). The study of landslides has drawn worldwide attention mainly due to increasing awareness of the socio-economic impact of landslides, as well as the increasing pressure of the urbanization on the mountain environment (Aleotti and Chowdhury 1999). Movement of mass of rock, debris or earth down a slope is simply called landslide (Cruden 1991). There are various physical factors that directly or indirectly contribute to landslides. These factors are the intrinsic and extrinsic factors. The intrinsic factors (geology, geomorphology, soil depth, soil type, slope, slope aspect, elevation, land use pattern, drainage pattern, lineament density, curvature and so on) and extrinsic factors (rainfall, earthquakes and volcanoes) are used to determine landslide hazard in an area (Dai et al. 2001; Dahal et al. 2008).

Varnes (1984) has defined landslide hazard as the probability of occurrence of a potentially damaging landslide phenomenon within a specified period of time and within a given area. Landslide hazard zonation is defined as the mapping of areas with an equal probability of occurrence of landslides within a specified period of time (Varnes 1984).Various techniques such as heuristic, statistical and deterministic approaches have been developed for the landslide hazard and susceptibility assessment (e.g. Pathak 2016; Dahal et al. 2012; Lee 2007; Guzzetti et al. 1999). For the present study, statistical approach "multivariate logistic regression" analysis method is used. A logistic regression model works within the framework of a Geographic Information System (GIS) to map landslide hazards in a mountainous environment (Chen and Wang 2007; Pokhrel and Pathak 2016).

\section{STUDY AREA}

Present study is carried out along the Marsyangdi River basin from Khudi to Tal. The study area lies between the latitude 


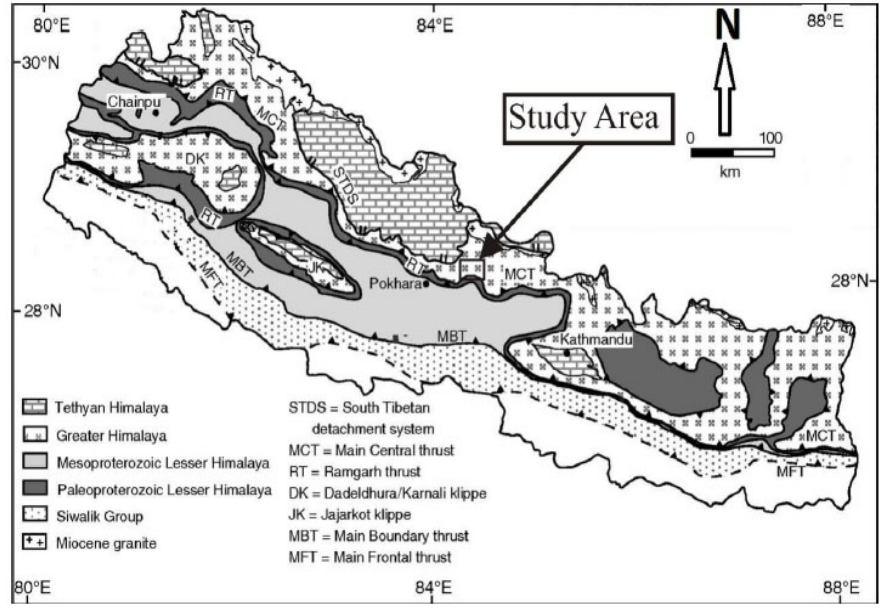

Fig. 1: Location map of the study area

$28^{\circ} 15^{\prime} 00^{\prime \prime}$ to $28^{\circ} 30^{\prime} 00^{\prime \prime}$ and longitude $84^{\circ} 20^{\prime} 00^{\prime \prime}$ to $84^{\circ} 30^{\prime} 00^{\prime \prime}$ (Fig. 1). Lamjung District covers most of the study area towards south while some part towards north lies in Manang District. The study area covers portion of famous Annapurna Base Camp trekking route. The area comprises of rugged and steep topography which is indicated by large variation in the altitude (i.e. from $820 \mathrm{~m}$ in Bhulbhule to $2047 \mathrm{~m}$ in Dahare). Some areas are difficult to reach in field. Marsyangdi River is the major drainage of the area flowing from north to south. Myardi Khola, Nadi Khola, Khudi Khola, Bhalam Khola are the principal feeders of Marsyangdi River.

\section{MATERIALS AND METHODS}

Landslide inventory map was prepared based on the number of historic and recent satellite images and field data collection. The topographic map of the Department of Survey, Government of Nepal and the Google Earth images are considered as basic data sources for preparing landslide database. Fig. 2 below shows the methods and factors adopted during the hazard analysis.

Total of 51 landslides were recognized during field visit and also using the aerial photographs. There is heterogeneous distribution of landslide over the area. About $70 \%$ of total landslides are used as training data set to assess predicted probability values and remaining 30\% landslide are used as validation data to calculate the success rate.

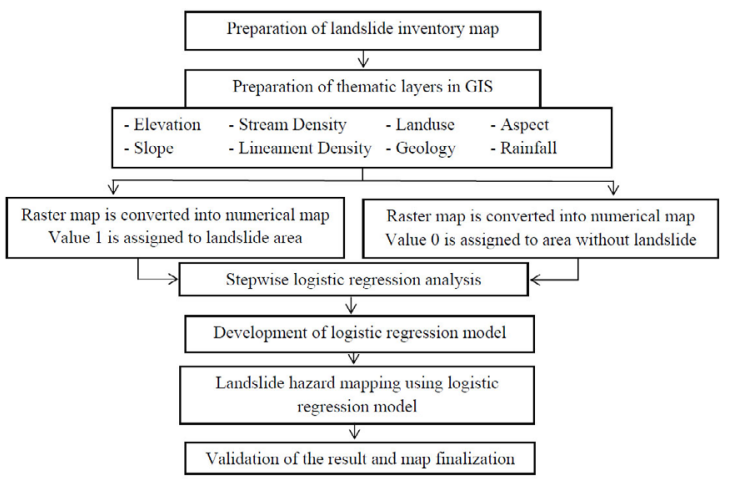

Fig. 2: Flowchart of the methodology (Modified after Dai et al. 2001)
The landslide inventory map showing the training data and validation data along with the land use map is shown in Fig. 3. The causative factors used in the landslide hazard analysis are the Digital Elevation Model (DEM) derived parameters (slope, aspect and elevation) and others are stream density, lineament density, land use, geology and rainfall. Among the parameters used, rainfall is only the extrinsic factor used in the analysis. The factors maps are classified into different classes which are shown in Fig. 4.

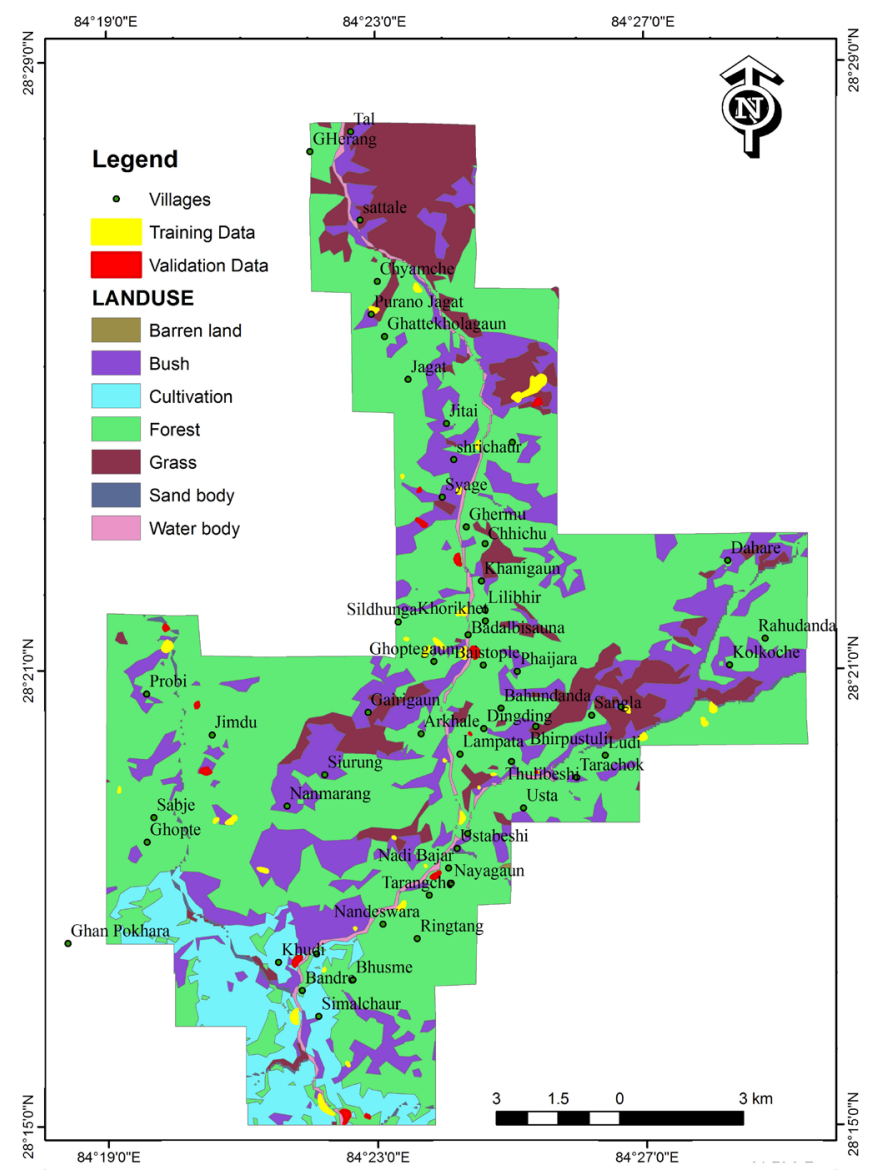

Fig. 3: Landslide inventory map shown with validation data and training data overlain on land use map.
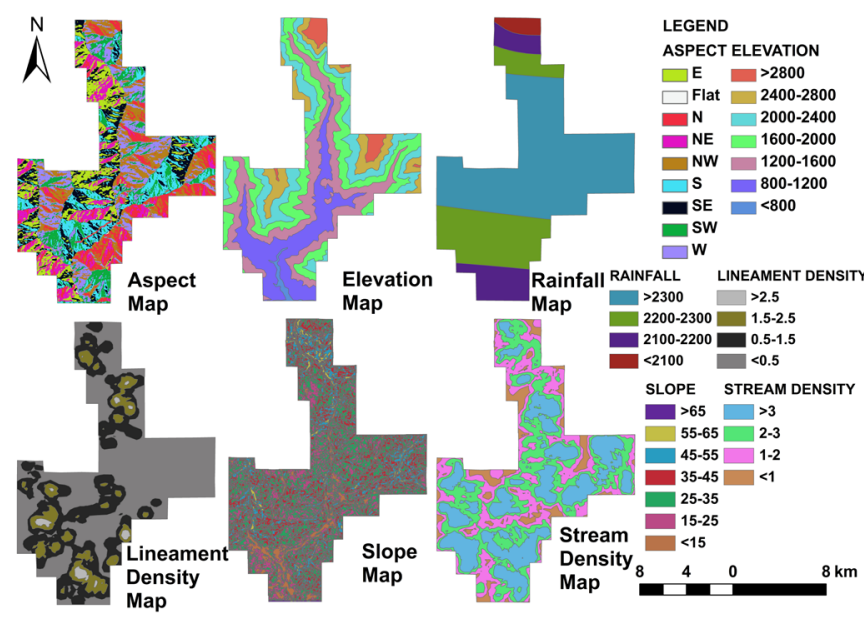

Fig. 4: Causative factor maps used in the hazard analysis with their classes. 
Geology of the area is also considered as one of the causative factors for the landslide hazard analysis. In geology, lithodomain map of the area is prepared at the scale of 1:50,000. The litho-domain map covers the rock type present in the study area as well as the terrace material of Marsyangdi River. The main rock types present in the area are graphitic schist, pelitic schist, psammatic schist, dolomite, quartzite and gneiss of sedimentary origin that is rich in mica such as banded gneiss, kyanite gneiss and garnet gneiss as shown in Fig. 5. Structurally, the area lies in the shear zone of the Main Central Thrust (MCT).

The database for the logistic regression model was prepared in GIS. All input data were converted into raster format. From all input data, point values were extracted at the location point of $\mathrm{X}$ and $\mathrm{Y}$ co-ordinate in GIS using "Extract values to point" tool. Statistical Packages for Social Science (SPSS) software was used to estimate the regression coefficient and to calculate the value of area under curve to determine the prediction rate and succession rate.

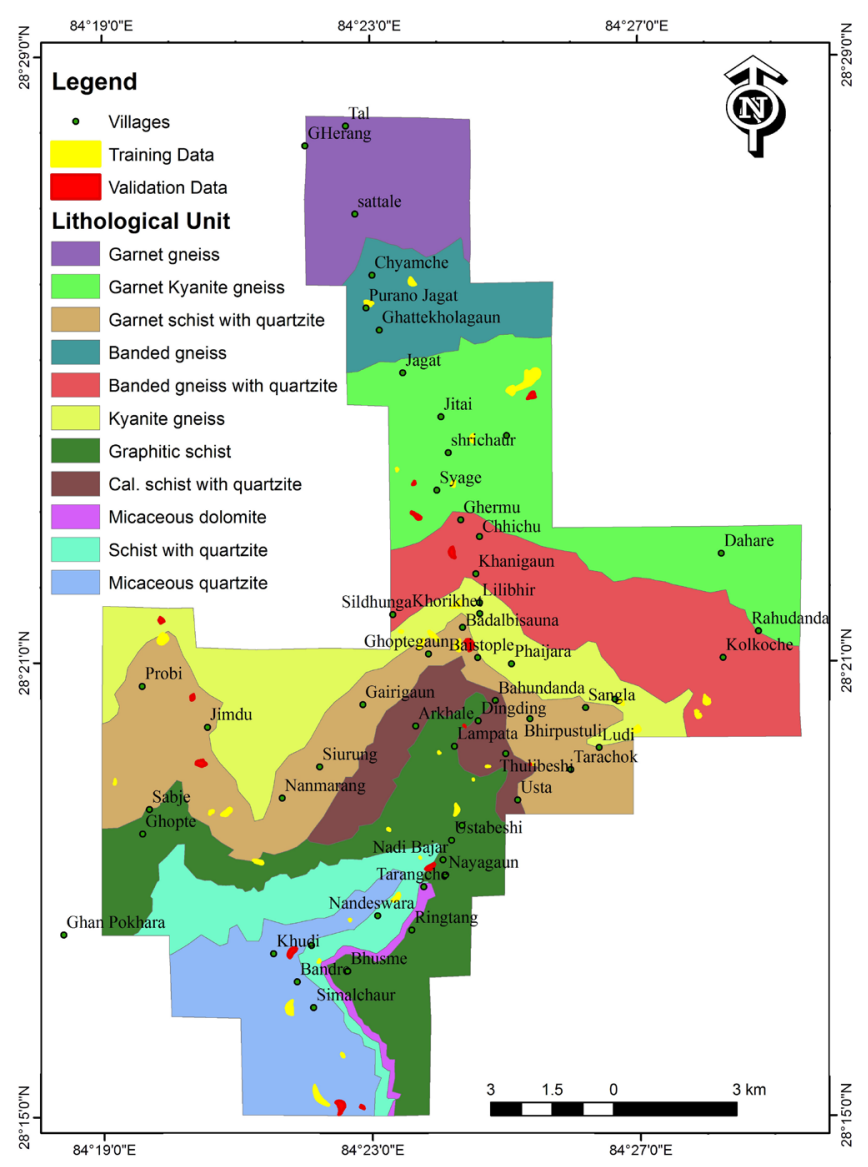

Fig. 5: Lithological map of the study area.

\section{RESULTS AND DISCUSSION}

Logistic regression is useful when the dependent variable is binary or dichotomous. The dependent variables for analysis is either the absence or presence of landslide i.e. pixel with landslide and pixel without landslide. The pixel with landslide is given Id ' 1 ' and for pixel without landslide Id ' 0 ' is given. The Landslide Hazard Index (LHI) obtained from the logistic regression method from SPSS is shown in Table 1. The elevation class between 800-1200 m, western aspect and slope angle between $25^{\circ}-35^{\circ}$ shows the highest degree of LHI. In geology the graphitic schist has the highest degree of LHI.

Different statistical parameters obtained after logistic regression analysis and computation in SPSS is shown in Table 2. Hosmer-Lemeshow test shows that the significance of ChiSquare is 0.412 which is greater than 0.05 which means the goodness-of-fit of the equation can be accepted. Greater the value for this test, higher is the significance of the work. In the Hosmer-Lemeshow test, if significance of Chi-Square value is less than 0.05 the logistic regression model cannot be accepted (Zhu and Huang 2006, Chen and Wang 2007). The value of Cox and Snell R2 and Nagelkerke R2 gives the reliability of the model. Higher the value of R2, more the model is reliable and vice-versa.

The logistic regression equation obtained after logistic regression modeling of the area is given below:

$\log (\mathrm{P} /(1-\mathrm{P}))=-2.614-(0.731$ *Elevation $)+\left(0.333^{*}\right.$ Slope $)-$ $(0.112 *$ Aspect $)-(0.097 *$ Lineament Density $)-(0.112 *$ Stream Density $)+(0.132 *$ Rainfall $)+(0.132 *$ Lithology $)-$ $(0.97 *$ Landuse $)$

The Receiver Operating Characteristic Curve (ROC) is used for the validation of the result obtained from the logistic regression analysis. The Receiver Operating Characteristic Curve gives the area under the curve and it is a measure of goodness of fit. The ROC curve of the training data account the success rate of the model (Fig. 6a) and the ROC curve of the validation data accounts for the prediction rate of the model (Fig. 6b). The ROC area under the curve for success rate is 0.747 and that for the prediction rate is 0.771 of the logistic regression model.

The predicted probability value obtained from logistic regression of validation data was considered for the zonation of hazard map. Considering the prediction rate of logistic regression from the ROC curve, five different classes of landslide hazard zones were identified in the study area. The break value of landslide probability used in the landslide hazard zonation is shown in Table 3. The landslide hazard zonation map of the Besi Shahar-Tal area using logistic regression method is shown in (Fig. 7) and most of the area lies in the low to very low landslide hazard zone.

The study area on the basis of the predicted probability value is divided into five different classes using the prediction data as Very Low $(<20 \%)$, Low $(20-40 \%)$, Medium (40$60 \%$ ), High (60-80\%) and Very High (80-100\%) susceptibility classes. The Receiver Operating Characteristics value should be greater than 0.5 (Hosmer and Lemeshow 2000) for the valid regression model, which is greater than 0.5 in present study that strongly supports that the model can be considered as an acceptable one. 
Acharya and Pathak

Table 1: Classes of the parameter and their Landslide Hazard Index (LHI).

\begin{tabular}{|l|l|l|l|l|l|}
\hline Elevation, $\mathbf{m}$ & LHI & Slope & LHI & Aspect & LHI \\
\hline$<800$ & 8.00971 & $<15$ & 10.2112 & Flat & 0.189528 \\
\hline $800-1200$ & 54.3019 & $15-25$ & 17.2474 & North-East & 7.283451 \\
\hline $1200-1600$ & 27.1731 & $25-35$ & 28.8225 & East & 11.7547 \\
\hline $1600-2000$ & 8.4445 & $35-45$ & 24.889 & South-East & 14.00947 \\
\hline $2000-2400$ & 1.77142 & $45-55$ & 11.4031 & South & 12.59784 \\
\hline $2400-2800$ & 0.26958 & $55-65$ & 3.60556 & South-West & 10.26522 \\
\hline$>2800$ & 0.02976 & $>65$ & 3.82131 & West & 16.32282 \\
\hline & North-West & 15.67357 & & & \\
\hline Stream density & LHI & Land use & LHI & North & 11.9034 \\
\hline$<1$ & 9.46432 & Cultivation & 14.2409 & & \\
\hline $1-2$ & 28.4687 & Vegetation & 62.1568 & Lithology & LHI \\
\hline $2-3$ & 36.6067 & Grass & 5.78356 & Garnet gneiss & 1.241606 \\
\hline$>3$ & 25.4603 & Bush & 15.2814 & Garnet-Kyanite-gneiss & 9.917199 \\
\hline & & Sand & 0.61576 & Banded gneiss & 3.012016 \\
\hline Lineament density & LHI & Barren land & 0.00737 & Banded gneiss with quartzite & 8.733392 \\
\hline$<0.5$ & 56.9397 & Water body & 1.91422 & Kyanite gneiss & 7.316961 \\
\hline $0.5-1.5$ & 35.384 & & & Garnet schist with quartzite & 13.92484 \\
\hline $1.5-2.5$ & 6.80498 & Rainfall, mm & LHI & Graphitic schist & 22.11169 \\
\hline$>2.5$ & 0.87132 & $<2100$ & 0.13442 & Calc schist and quartzite & 6.774209 \\
\hline & & $2100-2200$ & 16.5495 & Micaceous dolomite & 0.865195 \\
\hline & & $2200-2300$ & 25.8547 & Schist with quartzite & 8.440684 \\
\hline & & $>2300$ & 57.4614 & Micaceous quartzite & 17.66221 \\
\hline & & & & \\
\hline & & & & \\
\hline & & & & & \\
\hline & & & & & \\
\hline
\end{tabular}
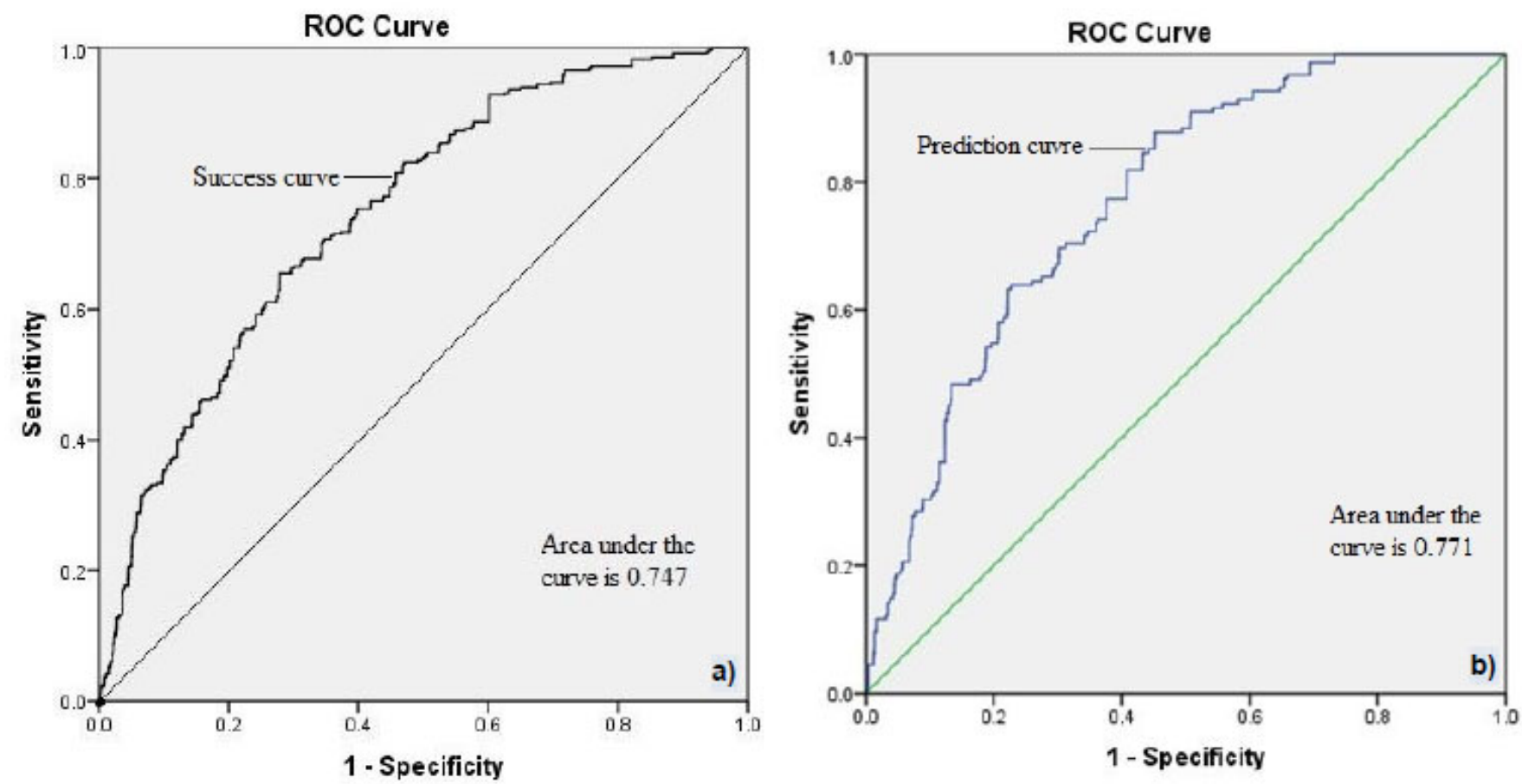

Fig. 6: (a) ROC area under curve training data and, (b) ROC under curve validation data. 
Table 2: Overall statistics of Logistic Regression Analysis and ROC value for training data.

\begin{tabular}{|l|l|l|}
\hline Cox and Snell $\mathrm{R}^{2}$ & Nagelkerke $\mathrm{R}^{2}$ & $\begin{array}{l}\text { Receiver Operating } \\
\text { Characteristic (ROC) } \\
\text { Curve }\end{array}$ \\
\hline 0.002 & 0.060 & 0.747 \\
\hline \multicolumn{3}{|c|}{ Hosmer and Lemeshow Test } \\
\hline Chi-Square & $\begin{array}{l}\text { df (degree of } \\
\text { freedom) }\end{array}$ & Significance \\
\hline 8.218 & 8 & 0.412 \\
\hline
\end{tabular}

Table 3: Table showing different hazard zonation based on predicted probability values.

\begin{tabular}{|l|l|l|}
\hline $\begin{array}{l}\text { Cumulative \% Predicted } \\
\text { Probability }\end{array}$ & $\begin{array}{l}\text { Predicted } \\
\text { Probability } \\
\text { values }\end{array}$ & $\begin{array}{l}\text { Susceptibility } \\
\text { class }\end{array}$ \\
\hline$<20 \%$ & 0.00214 & Very Low \\
\hline $20-40 \%$ & 0.0036 & Low \\
\hline $40-60 \%$ & 0.00574 & Medium \\
\hline $60-80 \%$ & 0.00985 & High \\
\hline $80-100 \%$ & 0.06724 & Very High \\
\hline
\end{tabular}

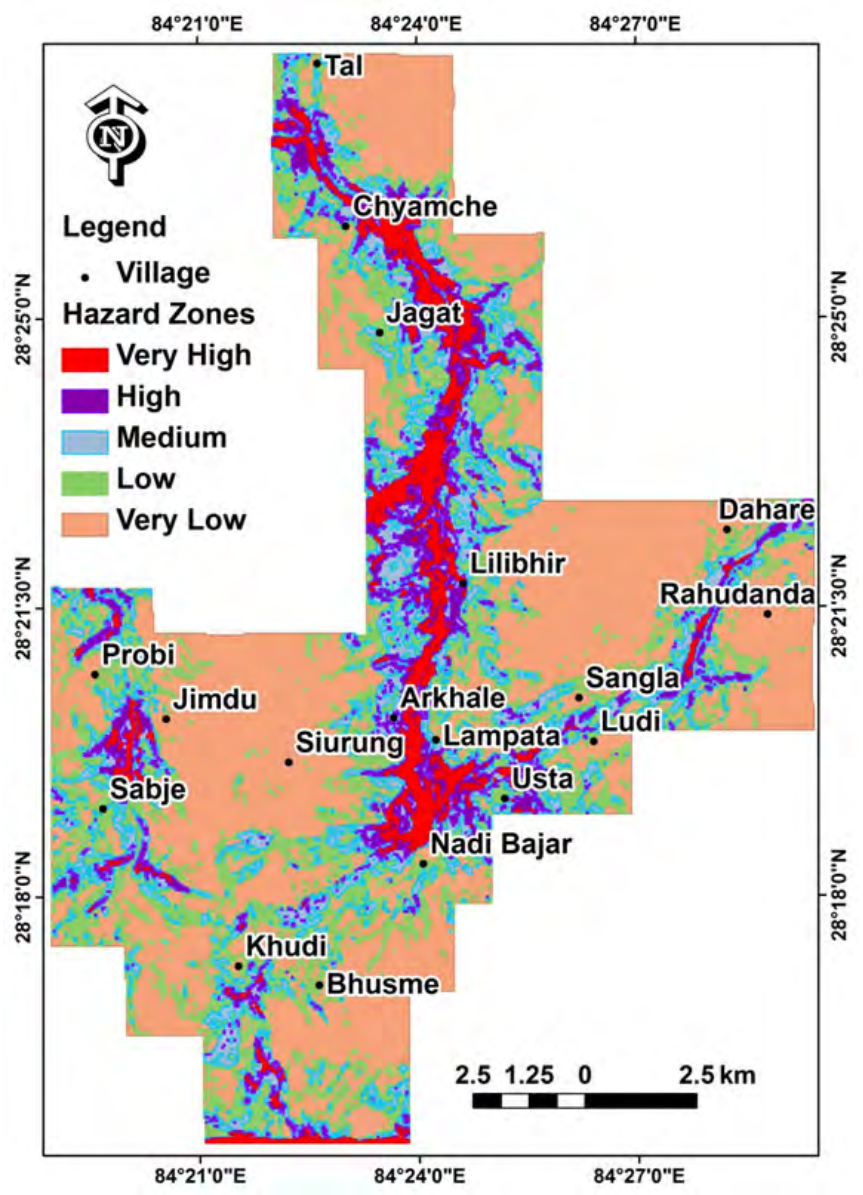

Fig. 7: Landslide hazard map of the Besi-Shahar-Tal area.
Likewise, the significance of chi-square is 0.412 for training data, suggesting the goodness-of-fit as per Hosmer and Lemeshow test. The $\mathrm{R}^{2}$ value of Nagelkerke is $0.06(>0.05)$ for training data and $0.111(>0.05)$ for validation data. Higher the value of $\mathrm{R}^{2}$, more reliable is the result. Thus the Nagelkerke value validates the reliability of result. Based on the positive results of the various statistical parameters, the landslide hazard model for the study area has been acceptable and is supposed to represent the field condition.

\section{CONCLUSIONS}

Logistic regression model has been applied to prepare landslide hazard map of the study area. The Receiver Operating Characteristic curve shows both good prediction and succession rate for the regression model used for hazard mapping. Hosmer Lemeshow test shows significance of the landslide hazard map prepared through logistic regression model using above parameters. The Nagelkerke value also indicates that the model is reliable in this area using above causative factors for the landslide occurrence. The predicted probability value is divided into five different classes as Very Low Hazard Zone, Low Hazard Zone, Medium Hazard Zone, High Hazard Zone and Very High Hazard Zone. Most of the area lies within Very Low Hazard Zone to Low Hazard Zone. The high hazard zone is mostly lying along the Marsyangdi River.

\section{ACKNOWLEDGEMENT}

This paper is based on research financed under the Climate Change Research Grants Program implemented by the Nepal Academy of Science and Technology (NAST). The Program is part of the Mainstreaming Climate Change Risk Management in Development project. This project is a component of Nepal's Pilot Program for Climate Resilience and is executed by the Ministry of Science, Technology and Environment, (Nepal), financed by the Climate Investment Funds, administered by the Asian Development Bank. The authors would like to extend sincere thanks to the Central Department of Geology, Tribhuvan University, for providing necessary facility to carry out the research.

\section{REFERENCES}

Aleotti, P., and Chowdhury, R., 1999, Landslide hazard assessment: summary review and new perspectives. Bull. Engg. Geol. Environ., v. 58, pp. 21-44.

Chen, Z., and Wang, J., 2007, Landslide hazard mapping using logistic regression model in Mackenzie Valley Canada. Natural Hazards, v. 42, pp. 75-89.

Crozier, M. J., and Glade, T., 2005, Landslide Hazard and Risk: Issues, Concepts and Approach. In: Landslide hazard and risk, Glade, T., Anderson, M., and Crozier, M., Chichester, Wiley, pp. $1-40$.

Cruden D. M., 1991, A simple definition of a landslide. Bull. Int. Asso. Engg. Geol., v. 43, pp. 27-29.

Dahal, R. K., Hasegawa, S., Bhandary, N. P., Poudel, P. P., Nonomura, A., and Yatabe, R., 2012, A replication of landslide hazard mapping at catchment scale. Geomatics, Natural Hazards and Risk. doi:10.1080/19475705.2011.629007.

Dahal, R. K., Hasegawa, S., Nonomura, A., Yamanaka, M., Dhakal, S., 


\section{Acharya and Pathak}

and Paudyal, P., 2008, Predictive modeling of rainfall-induced landslide hazard in the Lesser Himalaya of Nepal based on weights-of-evidence. Geomorphology, v. 102, pp. 496-510.

Dai, F. C., Lee, C. F., Li, J., and Xu, Z. W., 2001, Assessment of landslide susceptibility on the natural terrain of Lantau Island, Hong Kong, Environ. Geol., v. 40, pp. 381-391.

Guzzetti, F, Carrara, A., Cardinali, M., and Reichenbach, P., 1999, Landslide hazard evaluation: a review of current techniques and their application in a multi-scale study. Geomorphology, v. 31, pp. 181-216.

Hosmer, D. W., and Lemeshow, S., 2000, Applied Logistic Regression. John Wiley and Sons, Inc, Hoboken, NJ.

Lee, S., 2007, Comparison of landslide susceptibility maps generated through multiple logistic regression for three test areas in Korea. Earth Surface Processes and Landforms, v. 32, pp. 2133-2148.

Pathak, D., 2016, Knowledge based landslide susceptibility mapping in the Himalayas. Geoenvironmental Disasters, 3:8. doi: 10.1186/s40677-016-0042-0.

Pokhrel, P., and Pathak, D., 2016, Landslide susceptibility mapping of southern part of Marsyangdi River basin, west Nepal using logistic regression method. International Jour. Geomatics Geosci., v. 7(1), pp. 24-32.

Pradhan, B., Singh, R. P., and Buchroithner, M. F., 2006, Estimation of stress and its use in evaluation of landslide prone regions using remote sensing data. Advances in Space Research, v. 37 , pp. 698-709.

Varnes, D. J., 1984, Landslide hazard zonation: a review of principles and practice. Natural hazards no 3, 61p. UNESCO, Paris.

Zhu, L., and Huang, J., 2006, GIS-based logistic regression method for landslide susceptibility mapping in regional scale. Jour. Zhejiang University Science A, 7, pp. 2007-2017. 